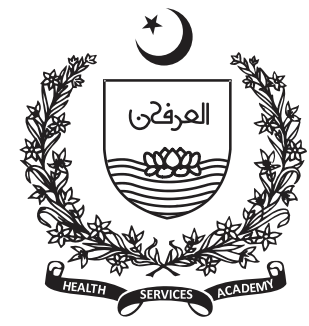

Fauji Foundation Islamabad

Corresponding Author: Fizah Mahnoor Khan Email: drfizahpt@gmail.com

\section{Screen Time Related Musculoskeletal Symptoms among Adolescents: A Cross Sectional Survey in Twin Cities}

Fizah Mahnoor Khan, Mahwish Hayee Shahid, Maham Nasir, Aqdas Karamat, Ch Abdullah

Abstract

Background: The objectives were to evaluate the frequency of musculoskeletal symptoms related to screen time and to determine the mostly affected body parts with musculoskeletal symptoms

Methods: A Cross-sectional survey was conducted on 150 students from February to May 2018 selected via convenience sampling technique. Data was collected from students of twin cities having screen time more than 3 hour's using validated questionnaires including

The Nordic Musculoskeletal Questionnaire (NMQ) to assess musculoskeletal symptoms and self-structured questionnaire for screen time and demographics. Data was analyzed using SPSS v.21.

Results: Mean age of the population was $15 \pm 2.7$ years. Mean screen time score was computed as 6.45 hours with 10 hours highest screen time observed of 6 participants. Mean musculoskeletal involvement was computed as $85.3 \%(n=128)$ in last 12 months of which $28.9 \% \quad(n=66)$ had neck pain, $21.9 \%(n=50)$ had lower back pain whereas $14.9 \%, 11.4 \%$ had shoulder and upper back involvement. In last 7 days $25.7 \%$, participants had pain in neck area and $18.3 \%$ in lower back. $83.5 \%$ participants didn't visited physicians for their respective condition. significant relation of screen time was observed with the musculoskeletal symptoms.

Conclusion: Screen time severely influence musculoskeletal symptoms especially neck and lower back muscle, presence of high number of musculoskeletal symptoms among adolescent is alarming and shows the need of adequate measures to address these problems

Keywords: Screen time, musculoskeletal symptoms, adolescents, neck pain

\section{Introduction}

W the advent of digital platforms and devices, the average human screen time has increased to an alarmingly high value. This overreliance on digital screens is the root cause of various musculoskeletal disorders. Screen time is the time spent on screen-based activities such as TV, Computers, and Mobiles etc. Standard screen time is less than 2 hours per dav.(1) Use of screen devices has increased drastically over the last decade and there are concerns that their excessive is associated with musculoskeletal(MSK) problems. A rising prevalence of physical complaints such as neck pain, low back pain and shoulder pain has been reported for adolescent population (2). These parallel trends in increasing MSK problems in adolescents and high screen time use might be related. A suggestive 
mechanism is that prolong screen time activities leads to sustained muscle tension and lack of recovery from this subsequently causes MSK pain such as low back pain and neck ache majorly (3). Studies have examined different health effects of screen, and symptoms in the musculoskeletal system have been reported (4). Musculoskeletal pain effect health problems not only in elder population but also in adolescents. Adolescents every day activities like school life is adversely effected by Musculoskeletal symptoms as it cause school absenteeism.(5)The use of computers, the Internet, and mobile phones, playing digital games and viewing television are related to Neck shoulder pain and Low back pain and Frequent computerrelated activities are an independent risk factor for neck shoulder pain and low back pain. (6) Daily use of computers exceeding 2-3 hours, a threshold for Neck shoulder pain and exceeding 5 hours for low back pain. Research reported this pain lasting longer than 3 months, which is a very long time and will hinder in performing everyday activities.(7)

Cross sectional association between screen based activities and musculoskeletal complaints was studied, they observed an association that indicated that time spent on screen based activities is a contributing factor to physical complaints. (8) the prevalence ratios were significantly increased of neck and upper-extremity symptoms, eyestrain and headache in upper secondary school students using computers $>56$ hours/week. Exposure-response relationships were indicated for the aforementioned associations. So researchers concluded that the students were not protected from computer-related health complaints.(9) $91.5 \%$ of children has unacceptable risky smartphone usage posture. (10)

Findings of this study will help increase the awareness of high prevalence of increased screen time related musculoskeletal symptoms in the current area adolescent, so health care worker could work on its prevention.

\section{Methodology}

An Observational study Cross-sectional survey was conducted on 150 adolescents. The calculated sample size was 150 .(11) Duration was from February 2019 May 2019 selected via Non-Probability purposive sampling. Inclusion Criteria of Age 12-19 years, Screen time more than 3 hours, Male and female and Exclusion criteria of any co-morbidity. Data was collected from the private school students of twin cities having screen time more than 3 hour is using validated questionnaires including The Nordic Musculoskeletal Questionnaire (NMQ) to assess musculoskeletal symptoms (12) and self-structured questionnaire for screen time and demographics. Before conducting research written consent was taken from the adolescents. All the statistical data was analyzed through SPSS 21 version.

\section{Results}

Mean age of the population was $15 \pm 2.7$ years. Mean \pm SD screen time score was computed as $5.2 \pm 2.1$ hours with 10 hours highest screen time observed of 6 participants. Mean musculoskeletal involvement was computed as $85.3 \%(n=128)$ in last 12 months of which $28.9 \%(n=66)$ had neck pain, $21.9 \%(n=50)$ had lower back pain whereas $14.9 \%, 11.4 \%$ had shoulder and upper back involvement. In last 7 days $25.7 \%$, participants had pain in neck area and $18.3 \%$ in lower back. $83.5 \%$ participants did not visited physicians for their respective condition. Significant relation of screen time was observed with the musculoskeletal symptoms. (Table: 1) Mean screen time score was computed as $5.2 \pm 2.1$ hours per day in 150 participants with the highest screen time of 9 hours per day, observed in 3 participants (Table: 2) The percentage of musculoskeletal symptoms observed in 150 adolescents in the last 12 months was $85.3 \%$, and 73.7 $\%$ in the last 7 day. (Table: 3) Highest involved segment is neck with $30.70 \%$ and after that is lower back with $21.90 \%$. (Figure: 1) Highest involved segment neck in last 7 days with percentage of 21.10. After that lower back with $17.50 \%$. (Figure: 2 )

Pearson chi square was applied to check association between screen time and musculoskeletal symptoms $\mathrm{P}$ value was less than 0.005 .

Table 1. overall view of age in percentage

\begin{tabular}{|c|c|}
\hline Age (years) & Percentage \\
\hline Mean \pm SD & $15 \pm 2.7$ \\
\hline 12years & $9.6 \%$ \\
\hline 13years & $14.9 \%$ \\
\hline 14years & $17.5 \%$ \\
\hline 15years & $14.0 \%$ \\
\hline 16years & $16.7 \%$ \\
\hline 17years & $8.8 \%$ \\
\hline 18years & $5.3 \%$ \\
\hline 19years & $13.2 \%$ \\
\hline
\end{tabular}


Table 2. Use of Screen per day (hours)

\begin{tabular}{|c|c|}
\hline Number of hours & Percentage \\
\hline Mean \pm SD & $5.2 \pm 2.1$ \\
\hline 3 hours & $14.0 \%$ \\
\hline 4 hours & $30.7 \%$ \\
\hline 5 hours & $27.2 \%$ \\
\hline 6 hours & $12.3 \%$ \\
\hline 7 hours & $7.9 \%$ \\
\hline 8 hours & $5.3 \%$ \\
\hline 9 hours & $2.6 \%$ \\
\hline
\end{tabular}

Table 3. Musculoskeletal symptoms

\begin{tabular}{|c|c|}
\hline $\begin{array}{c}\text { Musculoskeletal } \\
\text { symptoms in last 12 } \\
\text { months }\end{array}$ & $\begin{array}{c}\text { Musculoskeletal } \\
\text { symptoms in last 7 } \\
\text { days }\end{array}$ \\
\hline $\mathrm{n}=128(85.3 \%)$ & $\mathrm{n}=110(73.7 \%)$ \\
\hline
\end{tabular}

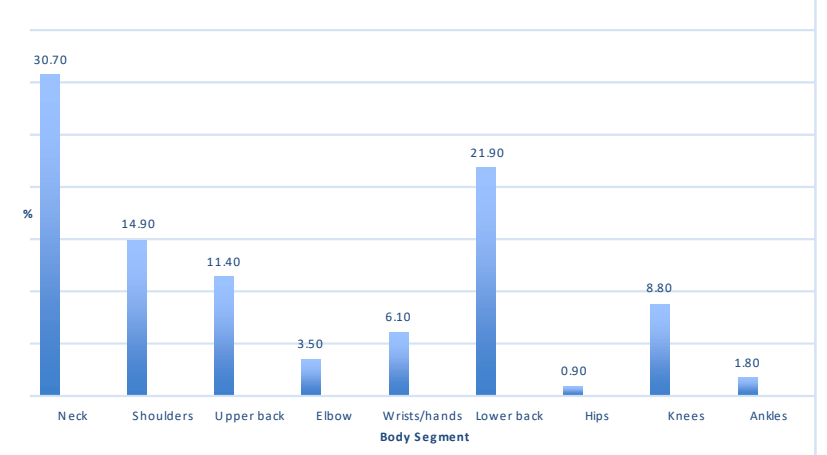

Figure 1. Body segment, Musculoskeletal Issues Encountered in Last 12 Months

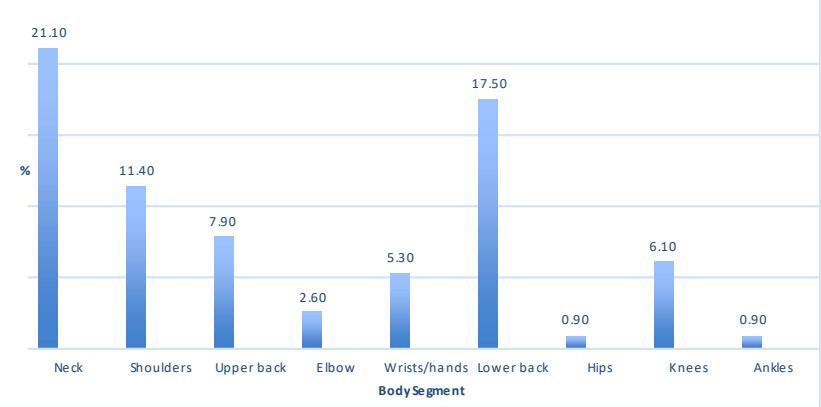

Figure 2. Body segment, Musculoskeletal Issues Encountered in the Last 07 Days

\section{Discussion}

According to our study screen time severely influences musculoskeletal symptoms, especially the neck and lower back muscles. In a previous study, results indicate that 14 or more hours of computer use in a week can lead to moderate to severe lower back and head pain, with a marked impact on the day-to-day life of the affected adolescents. In the study, the rate of the presence of these symptoms increased with age and a higher intensity of pain was reported by girls as opposed to boys. In our study, mean screen time reported was 6.45 hours and maximum physical complaints were reported in neck region and low back region.Data was collected from adolescents of the twin cities, with a daily screen time of more than 3 hours, using validated questionnaires, including The Nordic Musculoskeletal Questionnaire (NMQ) to assess musculoskeletal symptoms and the self-structured questionnaire which showed $85.3 \%$ of the participants had musculoskeletal issues related to screen use) in the last 12 months, of which $28.9 \%$ had neck pain, $21.9 \%$ had lower back pain whereas $14.9 \%$ and $11.4 \%$ had shoulder and upper back involvement respectively in a similar study Paula T. Hakala found a relation of frequent use of computers with an increased neck,lower back, and shoulder pain in adolescents. $26 \%$ of the participants experienced neck and shoulder pain, at least once a week, with the percentage of those with lower back pain being $12 \%$ in 14 to 18 years olds. The prevalence rates of NSP and LBP were also found to be higher in girls when compared to boys, with a marked increase with the increase in age.(13)

Previous research found that the use of computers, including gaming, and also watching tv caused headaches and backaches on a weekly basis. The connection between a higher screen-time and weekly headaches and backaches found by the study was weak but thoroughly consistent. The study supports our recent study in which 128 participants in the last 12 months, of which 66 had neck pain, 50 had lower back pain whereas $14.9 \%$ and $11.4 \%$ had shoulder and upper back involvement respectively. In the last 7 days, $25.7 \%$ of the participants had pain in the neck area and $18.3 \%$ in the lower back region.(2) The findings of our study are in line with a study conducted on secondary school students in which the students' use of computer use was found to be a contributing factor to neck and upper extremity symptoms, eyestrain, and headache.

Since laptops are highly portable, users often end up adopting non-optimal postures while using them, resulting in musculoskeletal pain at the least and injury at the worst. According to a study, conducted to 
show the prevalence of musculoskeletal issues in 100 girls who were frequent laptops user, the current body postures commonly adopted in lalptop usage were deemed ergonomically improper, leading to musculoskeletal pain. The results were in line with our results depicting a trend that the higher screen time creates musculoskeletal symptoms.(14) The rate of WRMSDs being reported by IT professionals is high. The most widely reported were neck pain problems, with $30 \%$ of IT professionals having experienced these symptoms in the 12-month timeframe preceding the study. This was closely followed by lower back issues and other musculoskeletal disorders such as pain at wrists, hands, and also shoulder problems.(15) Thus, it can be concluded that a strong relationship of BMI exits with WMSD and other forms of occupational psychosocial stress.(16)

On the other hand, result in our study showed significant relation of screen time was observed with the musculoskeletal symptoms. Work should be done to highlight the importance of addressing the different MSK issues related to an increased screen time. Interventional studies should be done to identify the different ways to decrease the total daily screen time.

\section{Conclusion}

A trend showing the relation of higher screen time with the presence of musculoskeletal symptoms was observed. Screen time severely influences musculoskeletal symptoms, the neck and lower back muscles are the most affected.

\section{Recommendation}

The presence of a high number of musculoskeletal symptoms among the adolescents is quite alarming and shows the need for adequate measures to address these problems. Educating to provide knowledge about safe use of smartphones to students, parents and relevant government agencies is very important.

\section{References}

1. Ting $\mathrm{CH}$, Chen YY. Smartphone addiction. Adolescent Addiction: Elsevier; 2020. p. 215-40.

2. Torsheim T, Eriksson L, Schnohr CW, Hansen F, Bjarnason T, Välimaa R. Screen-based activities and physical complaints among adolescents from the Nordic countries. BMC public health. 2010;10(1):324.

3. Miller GE, Chen E, Parker KJ. Psychological stress in childhood and susceptibility to the chronic diseases of aging: moving toward a model of behavioral and biological mechanisms. Psychological bulletin. 2011;137(6):959.
4. Szeto GP, Sham KS. The effects of angled positions of computer display screen on muscle activities of the neck-shoulder stabilizers. International Journal of Industrial Ergonomics. 2008;38(1):9-17.

5. Vervoort T, Logan DE, Goubert L, De Clercq B, Hublet A. Severity of pediatric pain in relation to school-related functioning and teacher support: an epidemiological study among school-aged children and adolescents. PAIN®. 2014;155(6):1118-27.

6. Hakala PT, Rimpelä AH, Saarni LA, Salminen JJ. Frequent computer-related activities increase the risk of neck-shoulder and low back pain in adolescents. The European Journal of Public Health. 2006;16(5):536-41.

7. Hakala PT, Saarni LA, Punamäki R-L, Wallenius MA, Nygård C-H, Rimpelä AH. Musculoskeletal symptoms and computer use among Finnish adolescents-pain intensity and inconvenience to everyday life: a crosssectional study. BMC musculoskeletal disorders. 2012;13(1):41.

8. Brindova D, Veselska ZD, Klein D, Hamrik Z, Sigmundova D, van Dijk JP, et al. Is the association between screen-based behaviour and health complaints among adolescents moderated by physical activity? International journal of public health. 2015;60(2):139-45.

9. Palm P, Risberg EH. Computer use, neck and upperextremity symptoms, eyestrain and headache among female and male upper secondary school students. Scandinavian Journal of Work, Environment \& Health. 2007:33.

10. Mongkonkansai J, Madardam U, Veerasakul S. Smartphone Usage Posture (Sitting and Lying Down) and Musculoskeletal Symptoms among school-aged children (6-12 years old) in Nakhon Si Thammarat, Thailand. 2020.

11. Barnett TA, O'Loughlin J, Sabiston CM, Karp I, Bélanger M, Van Hulst A, Lambert M. Teens and screens: the influence of screen time on adiposity in adolescents. American Journal of Epidemiology. 2010 Aug 1;172(3):255-62.

12. O'Sullivan PB, Beales DJ, Smith AJ, Straker LM. Low back pain in 17 year olds has substantial impact and represents an important public health disorder: a crosssectional study. BMC public health. 2012;12(1):100.

13. Hakala PT, Saarni LA, Ketola RL, Rahkola ET, Salminen JJ, Rimpelä AH. Computer-associated health complaints and sources of ergonomic instructions in computerrelated issues among Finnish adolescents: A crosssectional study. BMC Public Health. 2010;10(1):1-8.

14. Forsman Sjöberg A. Design guidelines: Study solutions for children: Ergonomic aspects of study solutions for 5 14-year-old children. 2019.

15. Das D, Kumar A, Sharma M. A systematic review of work-related musculoskeletal disorders among handicraft workers. International Journal of Occupational Safety and Ergonomics. 2018.

16. Stander BJ. An investigation into the prevalence and risk factors of occupational low back pain amongst commercial pilots registered with the South African Civil Aviation Authority 2015. 